\title{
POÉTICAS E POLÍTICAS DA RELAÇÃO: \\ APONTAMENTOS A PARTIR DA AÇÃO DE AILTON KRENAK NA \\ ASSEMBLÉIA CONSTITUINTE E SEU DESLOCAMENTO PARA ESPAÇOS \\ DE ARTE CONTEMPORÂNEA
}

\author{
Damiana Bregalda Jaenisch ${ }^{1}$
}
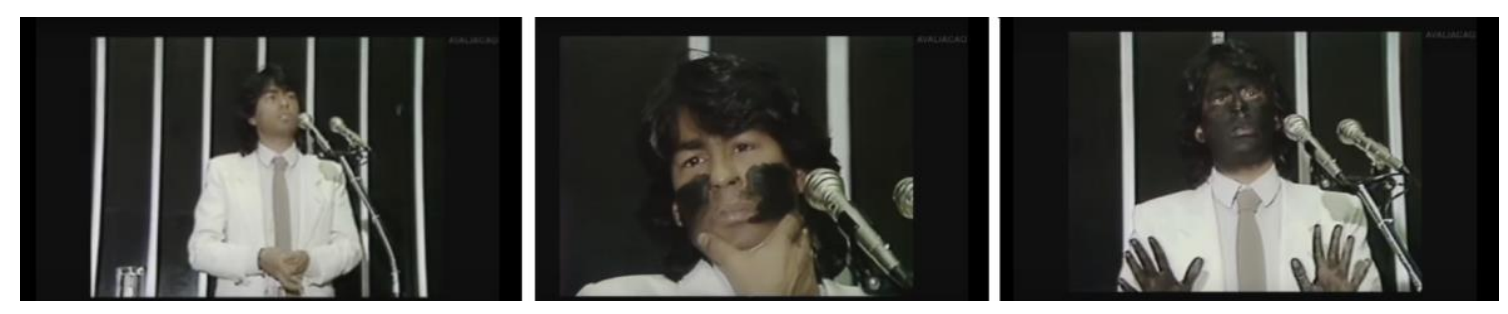

Fala de Ailton Krenak na Assembléia Constituinte. Fonte: Trailer do filme Índio cidadão? ${ }^{2}$

Eu espero não agredir com a minha manifestação o protocolo desta casa. Mas eu acredito que os senhores não poderão ficar omissos, os senhores não terão como ficar alheios a mais essa agressão movida pelo poder econômico, pela ganância, pela ignorância do que significa ser um povo indígena. Povo indígena tem um jeito de pensar, tem um jeito de viver. Tem condições fundamentais para sua existência e para a manifestação da sua tradição, da sua vida e da sua cultura que não coloca em risco e nunca colocaram a existência sequer dos animais que vivem ao redor das áreas indígenas, quanto mais de outros seres humanos. Eu creio que nenhum dos senhores nunca poderia apontar atos, atitudes da gente indígena do Brasil que colocaram em risco seja a vida, seja o patrimônio de qualquer pessoa, de qualquer grupo humano nesse país. E hoje nós somos alvo de uma agressão que pretende atingir na essência a nossa fé, a nossa confiança de que ainda existe dignidade, de que ainda é possível construir uma sociedade que sabe respeitar os mais fracos, que sabe respeitar aqueles que não têm o dinheiro para manter uma campanha incessante de difamação. Que saiba respeitar um povo que sempre viveu à revelia de todas as riquezas. Um povo que habita casas cobertas de palha, que dorme em esteiras no chão, não deve ser identificado de jeito nenhum como um povo que é inimigo dos interesses do Brasil, inimigo dos interesses da nação, e que coloca em risco qualquer desenvolvimento. $\mathrm{O}$ povo indígena tem regado com sangue cada hectare dos oito milhões de quilômetros quadrados do Brasil. E os senhores são testemunha disso. Eu agradeço a presidência desta casa, agradeço os senhores e espero não ter agredido com as minhas palavras os sentimentos dos senhores que se encontram nesta casa. (Fala de Ailton Krenak na Assembléia Constituinte de 1987. Fonte: Índio Cidadão?, 2014)

\footnotetext{
${ }^{1}$ Universidade do Estado do Rio de Janeiro, Brasil.

2 Disponível em https://www.youtube.com/watch?v=kWMHiwdbM_Q Acessado em 11 de dezembro de 2016.
} 
Segundo Ailton Krenak, as imagens da ação que realizou em 1987 durante a Assembléia Constituinte foram recuperadas recentemente por Rodrigo Siqueira para realização do documentário Índio Cidadão? (2014), que trata do movimento de luta dos povos indígenas no Brasil pela conquista e manutenção de direitos, fazendo referência desde o movimento entorno da Constituinte até eventos recentes, como os de resistência a projetos de leis que tornam ainda mais difíceis os processos de demarcações de terras indígenas e a integridade destes territórios. Depois deste filme e de disponibilizadas as imagens de Krenak na internet, estas tem sido evocadas em diferentes espaços e plataformas, desde pinturas murais em espaço público (como realizada em São Paulo), em livros didáticos, e em exposições de arte: ela integrou a projeção de fragmentos de vídeos apresentada pelo coletivo Vídeo nas Aldeias na 32ª Bienal de São Paulo (2016) e as exposições “A Queda do Céu” (2015) e “Adornos do Brasil Indígena: Resistências Contemporâneas" ${ }^{3}$ (2016/2017). Me deterei aqui ao deslocamento destas imagens do contexto onde foram realizadas aos espaços de exposição de arte, buscando elencar instrumentos que possam ser produtivos para uma abordagem das relações entre artes indígenas e contemporânea, no sentido da ampliação de concepções acerca de arte e artista e de levar em conta a diferença irredutível dos modos de existência postos em relação.

\section{A ação de Ailton Krenak na Assembléia Constituinte}

Em 13 de agosto de 1987 é encaminhada por representantes da União das Nações Indígenas ${ }^{4}$ a Emenda Popular ao projeto de Constituição, propondo elaboração do capítulo sobre as populações indígenas. Dentre os pontos centrais estavam a demarcação dos territórios indígenas, o reconhecimento das culturas e tradições indígenas e dos direitos históricos destes povos, assegurando o usufruto dos recursos naturais existentes nestas terras como condição da economia interna e projeto de futuro dos povos indígenas (Ailton Krenak, imagens de arquivo no filme “Índio Cidadão?”). Ocorre que nesta mesma semana “o jornal "O Estado de São Paulo" passou a publicar diariamente durante uma semana a série de matérias intitulada "Os índios na

\footnotetext{
${ }^{3}$ Estas últimas foram realizadas respectivamente no Paço das Artes e no SESC Pinheiros, ambas em São Paulo com curadoria de Moacir dos Anjos e no caso da segunda em parceria com a equipe do MAE/USP. A equipe de curadoria da $32^{a}$ Bienal de São Paulo foi composta por Jochen Volz, Júlia Rebouças, Gabi Ngcobo, Lars Bang Larsen e Sofía Olascoaga.

${ }^{4}$ Organização criada em 1980, fruto do movimento indígena brasileiro nas décadas de 1970 e 1980.
} 
Constituição", veiculando denúncias sobre uma suposta "conspiração" internacional contra o Brasil, a pretexto da defesa de interesses indígenas na Constituinte" (CEDI, 1991: 20). Tratou-se de campanha que tentou criminalizar uma série de instituições nacionais e internacionais que apoiavam os direitos indígenas e que repercutiu no Congresso Nacional às vésperas da aprovação do relatório final da Comissão de Sistematização que preparava o projeto de constituição. Conforme informações do Centro Ecumênico de Documentação e Informação (CEDI, 1991:20), "várias autoridades do Executivo e Legislativo (...) além de alguns órgãos de imprensa, reproduziram e disseminaram as acusações".

Foi neste cenário que, em 4 de setembro de 1987, Ailton Krenak, como representante da União das Nações Indígenas, realiza na tribuna fala em defesa da Emenda Popular, buscando reverter a conjuntura política anti-indígena do Congresso Nacional. Vestindo terno e gravata, possivelmente em acordo com protocolo do Congresso, Krenak inicia seu discurso denunciando a falta de ética em jogo no processo da luta de interesses que afetam os direitos indígenas e prossegue sua fala articulando-a com o gesto de pintar seu rosto com tinta preta, em referência à pintura indígena de jenipapo, que pouco antes de concluir sua fala cobre todo seu rosto. Sua fala eloqüente, contundente e sensível ganha ainda mais força com o gesto da pintura, que traz novas camadas sensíveis e discursivas, intensificando sua presença e fala.

Conforme sugere Rodrigo Siqueira em entrevista à rádio Yandê, a fala de Ailton Krenak foi o ato de protagonismo mais marcante da Assembléia Nacional Constituinte e decisivo para aprovação dos artigos 231 e 232 da Constituição, tendo gravado nos anais da Constituinte a denúncia do histórico de genocídio e ataques aos Povos Indígenas no Brasil (Rádio Yandê, 2015). O gesto abre margem a interpretações diversas: gesto de luto e luta, como sugere Rodrigo Siqueira, de resistência que não se dá apenas pelo discurso, mas na persistência de práticas culturais, incluindo a pintura corporal e o uso de adornos e artefatos, propõe Marcos Grinspum Ferraz (2016) em coluna sobre a exposição Adornos do Brasil Indígena. 
O terno e gravata de cores claras e o discurso bem articulado - familiares e adequados ao contexto em questão - contrasta com o gesto da pintura de seu rosto com tinta preta, causando estranhamento e ruptura com aquele contexto e vinculando-o a um modo de ser específico ${ }^{5}$. A fala de Krenak, que descreve a histórica relação dos indígenas com o Estado, a sociedade brasileira e seus territórios, somada a seu gesto marcador da diferença - condensam a um só tempo as capacidades de resiliência e resistência dos povos indígenas e a demanda que sejam reconhecidos e respeitados na sua condição de sujeitos (lembrando que até a constituição de 1988 eram tutelados pelo estado) e na sua diferença. Nesta direção, a ação realizada por Ailton Krenak também se revela eficaz no questionamento e enfrentamento de outra questão em disputa naquele momento no Congresso Nacional: uma emenda pretendia restringir os direitos dos povos indígenas àqueles que não se encontravam em estágio de "aculturação", conceito sequer explicitado, que poderia limitar em grande medida a aplicação dos direitos. Segundo Ailton Krenak (no filme “Índio Cidadão?”, 2014) um indígena que soubesse falar português, que reconhecesse os símbolos nacionais ou cujo contato não tenha sido recente poderia ser identificado como "aculturado" e ter seus direitos negados, o que implicaria também que sobre seus territórios poderiam "incidir atividades garimpeiras, mineradoras, colônias agrícolas, a colonização direta sobre esses territórios".

Considerando pois, a importância da ação de Ailton Krenak no âmbito da Assembléia Constituinte no sentido de culminar a articulação e o movimento de luta dos povos indígenas das décadas de 1970 e 1980 num gesto tornado icônico e que contribuiu para a eficácia de todo o processo que resultou nos artigos 231 e 232 da Constituição de 1988, gostaria de prosseguir a uma possível análise desta ação enquanto ação ritual que dialoga de modo intenso e a partir de lógicas indígenas, propondo-se atuar no terreno das relações interétnicas e/ou com o estado. Para além da oralidade enquanto modo de transmissão de conhecimentos, gostaria de enfatizar a corporalidade enquanto lugar de investimento na produção e transformação da pessoa entre os povos indígenas, dada a ver na ação de Krenak.

\footnotetext{
${ }^{5}$ Conforme declaração de Ailton Krenak no filme "Índio Cidadão?", a presença de muitos indígenas vestidos com trajes de suas respectivas etnias, pintados, adornados, causou grande impacto e estranhamento no Congresso durante a Assembléia Nacional Constituinte. O acionar de elementos identitários tem sido recorrente nas manifestações políticas realizadas também nos últimos anos e é um dos aspectos enfatizados na exposição Adornos do Brasil Indígena: resistências contemporâneas.
} 
Conforme Victor Turner, os rituais de passagem se caracterizariam por serem realizados em momentos de crise ou de transição no âmbito das relações e estruturas sociais, o que bem poderia definir o cenário pós-ditadura militar e de abertura política em que foi realizada a Assembléia Constituinte. Neste sentido, muitos acontecimentos, mas me deterei na ação que vem sendo abordada, poderiam ser abordados como integrantes deste ritual ou estado de liminaridade, em que os indígenas se fizeram presentes enquanto atores, mobilizando-se para produzir as transformações que julgavam necessárias aos modelos de relação há séculos vigentes.

Ainda para Victor Turner e Richard Schechner, que por sua vez recorrem aos estudos de Van Gennep, os ritos de passagem seriam caracterizados por três principais momentos: de separação, de margem ou liminaridade e de agregação ou reintegração. Se tomarmos tais momentos para análise da ação realizada por Ailton Krenak, sua presença enquanto liderança e representante do movimento social na Assembléia poderia se configurar enquanto um momento de separação com relação a um período anterior da história: alguns anos antes movimentos sociais eram criminalizados e perseguidos e a conquista de um lugar de fala na condição de indígena rompia com o próprio estatuto jurídico vigente, que ainda os definia enquanto tutelados. Neste sentido, trata-se de período em que os papeis sociais/políticos se suspendem para serem reconfigurados.

No momento em que o gesto da pintura passa a integrar sua ação, a condição de liminaridade/margem se instaura, sobretudo na potência do gesto de romper e suspender procedimentos comuns ao tempo/espaço do Congresso Nacional pela via do ativamento de elementos referenciais a práticas indígenas. Tal deslocamento, um comportamento restaurado ou comportamento duplamente comportado, como Schechner (2013: 40) define performance traz no corpo a memória ${ }^{6}$, o conhecimento encorporado não apenas da pessoa que naquele momento assume caráter ambíguo, ocupando "espaço entre as posições atribuídas e ordenadas pela lei, pelos costumes, convenções e cerimonial" (Turner, 1974: 117), mas de todas as que Ailton Krenak representa naquele contexto. Neste sentido, a transformação corporal de que ele é protagonista e que naquele momento incide sobre sua pessoa, pretende reverberar no estatuto jurídico de todas as pessoas que ele ali representa. Cabe enfatizar que é o idioma da corporalidade que é acionado por Ailton Krenak em sua ação, lembrando que,

\footnotetext{
${ }^{6}$ Schechner busca em Grotowski tal elaboração referente ao papel do corpo na transmissão de
} conhecimentos. 
como é o caso entre diversos grupos indígenas brasileiros, é para o corpo da pessoa que se volta a atenção quando esta se encontra em período de transformação de seu status ou condição social. A intervenção no corpo marca a passagem, transformação e neste sentido e contexto, é inscrição da própria diferença com relação e na relação com as demais parcelas da sociedade brasileira.

Para Schechner, toda ação, inclusive as não desempenhadas apenas por seres humanos, pode ser analisada como performance. Para o autor, a performance seria um "amplo espectro" de atividades que vão desde o ritual e o play (em todas as suas variedades desconcertantes e de difícil definição) até formas populares de entretenimento, festas, atividades da vida diária, os negócios, a medicina e os gêneros estéticos do teatro, da dança e da música.” (Schechner, 2013: 37, 38). Neste sentido, chamo atenção para a definição de performance como atividade, ação ${ }^{7}$ e para o como ela pode ser produtiva na análise da ação de Krenak, uma vez que possibilita enfatizar que algo está acontecendo. Neste sentido, a pintura corporal é importante naquele contexto, mas não (só) por ser interessante em si - o efeito teria sido muito possivelmente diverso se Krenak tivesse subido ao palco com o rosto já pintado e realizado sua fala. $\mathrm{O}$ que confere grande potência àquele espaço/tempo específico é que ele é sede de um acontecimento ${ }^{8}$. A questão que nos interessa aqui, é pois, o que está acontecendo e como está acontecendo?

Muitas etnografias, e em grande medida aquelas voltadas ao estudo das artes indígenas, mas não somente, tem destacado que para os grupos ameríndios humanidade não é condição que está dada, mas precisa ser constantemente construída com base em uma série de intervenções, sobretudo corporais e que envolvem a relação com diferentes seres, humanos e não-humanos. Seria para a ação enquanto produtora de uma humanidade específica que estaria chamando atenção a ação de Krenak?

O ritual realizado por Ailton Krenak obteve sua eficácia, resultando na promulgação da Constituição de 1988, um marco na redefinição do estatuto jurídico dos povos indígenas, que passam da condição de tutela à condição de sujeitos de direito, tendo seus direitos territoriais reconhecidos, assim como sua cultura, língua costumes e

\footnotetext{
${ }^{7}$ Para Schechner performance poderia ainda ser definida pela implicação de três ações ou operações: ser/estar (se comportar); fazer (atividade de tudo que existe, dos quarks aos seres humanos); mostrar o que se faz (ligado à natureza dos comportamentos humanos) (apud Féral, 2008: 198)

${ }^{8}$ Tal como propõe Schechner a propósito das pinturas rupestres nas cavernas, mais que as pinturas em si e o que elas possam representar, elas são interessantes por revelarem espaços onde algo aconteceu. Nas palavras de Schechner: "As cavernas eram teatros. Eram espaços onde algo aconteceu" (Schechner, 2013:47).
} 
modos específicos de saber, fazer e viver, marcando o momento de agregação do ritual de passagem. Entretanto, a história pós Constituição de 1988 tem confirmado a premissa de que a condição desta humanidade, também na relação com os brancos, não está dada, mas precisa ser constantemente acionada, reivindicada e fruto do investimento de ações. Resistência e luta, assim como a produção de humanidade, são termos que remetem a ações.

\section{O vídeo de Krenak em exposições de arte contemporânea}

É pois, num contexto de constantes e crescentes ameaças à garantia dos direitos que conferem dignidade e humanidade aos indígenas brasileiros, que a ação de Ailton Krenak é retomada, reativada e exibida em diferentes contextos. Dentre estes contextos, como já referido, proponho dialogar com a exibição destas imagens nos espaços de exposições de arte contemporânea. Além de exibida na Bienal de São Paulo, junto ao trabalho assinado pelo Coletivo Vídeo nas Aldeias, ela também esteve presente em duas exposições organizadas por Moacir dos Anjos em São Paulo. A propósito da presença do vídeo na exposição "Adornos do Brasil Indígena”, o curador, em diálogo com Ferraz (2016), declara: "É muito interessante aquela fala, principalmente como ela é feita, porque está justamente no limite entre a pintura indígena como resistência e a performance artística”.

A partir do que Moacir dos Anjos propõe no catálogo da exposição, poderíamos entender "a pintura indígena como resistência" tanto em seus aspectos de afirmação identitária em relação a outros grupos indígenas e aos brancos, mas também em termos de resistência simbólica e cosmológica, "posto que adornos são, muitas vezes, elementos de comunicação com os espíritos que, nas cosmologias nativas, controlam o caos do mundo" (Anjos, 2016: 14) e finalmente, de resistência física, quando os adornos indicam que "não existe outra maneira de viver a vida livre senão mantendo-se em estado permanente de luta" (Anjos, 2016: 14). Mas como lê-la, enfim, na fronteira da performance artística? Nos comentários acerca da ação de Krenak ${ }^{9}$ no catálogo da exposição, é sugerido que sua voz e gesto conformam um enunciado situado entre a performance estética e a manifestação política onde imagem e discurso "se

\footnotetext{
${ }^{9}$ Este, em texto descritivo de sua biografia e ação é identificado como liderança indígena, mas tal texto integra o tópico "artistas contemporâneos que participam da exposição". Neste sentido, a posição entre sugerida por sua ação também se estende à forma como esta pessoa é referida.
} 
mesclam para exigir, no campo do sensível e no da razão, que se reparem os danos inflingidos aos indígenas e que se respeite a diversidade de modos de existir" (Adornos, 2016: 65).

Mesmo compreendendo que o domínio ao qual chamamos de "estético", que diz respeito às dimensões do sensível, não pode ser separado no contexto indígena das demais esferas da vida, sendo inclusive os aspectos estéticos parte fundamental dos rituais que visam ser eficazes, é interessante trazer mais elementos que possam subsidiar o diálogo e as aproximações que vem sendo feitas entre as artes indígenas e a arte contemporânea ou mais especificamente, a performance artística, tal como mencionada pelo curador.

Neste sentido, retornamos ao conceito de performance, buscando situar a definição do conceito ampliado proposto por Schechner, para quem qualquer atividade pode ser analisada como performance, na relação com uma definição mais restrita do termo, aplicada a um domínio específico das artes. Segundo Josette Féral (2008: 197; 200) a performance concebida como forma artística (performance art) e a performance concebida como ferramenta teórica de conceituação, como experiência e competência que inclui todos os domínios da cultura (tal como propõe Schechner) correspondem a dois grandes eixos a partir dos quais podemos pensar as artes hoje: o último propondo uma visão antropológica e intercultural, o primeiro uma visão mais estética, herdada da vanguarda e da arte da performance. O conceito proposto por Schechner, por sua vez, estaria marcado segundo a autora, pelo desejo político (ancorado na ideologia americana dos anos 1980 que perdura até hoje) de "reinscrever a arte no domínio do político, do cotidiano, quiçá do comum, e de atacar a separação radical entre cultura de elite e cultura popular, entre cultura nobre e cultura de massa" (Féral, 2008: 199).

Neste sentido, poderíamos apontar que o conceito de performance de Schechner emerge como um recurso teórico/político em grande medida afinado com práticas artísticas que emergem nos anos 1960 e se estendem às décadas seguintes, que também trazem consigo a marca de reinscrição da arte nos campos da cultura, do ritual, do cotidiano, do social, do político... redefinindo o que se entende por arte e redimensionando suas fronteiras. O próprio autor, ao propor uma análise comparativa entre teatro e ritual, pondera as transformações que as fronteiras que marcam suas diferenças e separações, sofrem com o tempo. Nesta comparação Schechner sugere que o teatro faz referência a representações de representações, sendo a relação estabelecida 
aquela entre personagem/ator e audiência/sociedade, com ênfase no entretenimento. Já nos rituais, dentre os quais ele toma como exemplo o sacrifício, a relação seria aquela entre vítima e sociedade. Estes, por sua vez seriam voltados à eficácia. Tanto as iniciações rituais como as performances teatrais operariam, para Schechner, processos de transformações, fazendo de uma pessoa, outra. Entretanto, as transformações sofridas durante os rituais seriam permanentes, enquanto nas performances teatrais, temporárias, ou seja, o performer recobra ao final da performance o seu próprio eu. A essas transformações temporárias o autor chama pois, "transportações" (Schechner, 1985 apud Müller, 2005: 79).

Tais distinções não implicariam dizer, porém que as performances teatrais não trazem consigo o elemento da eficácia, como já mencionado, não existindo nenhuma performance teatral que seja puramente voltada ao entretenimento ou ritual puramente eficaz (Schechner, 1994: 622). Nesta direção, Schechner propõe ainda em sua análise do teatro ocidental, um gráfico que ilustra a variação na relação entre eficácia e entretenimento ao longo da história do teatro e drama ocidental, chamando a atenção para o fato de que em meados das décadas de 1960 e 1970 (com a emergência do teatro experimental, político e de psicoterapias performativas) a eficácia teria usurpado a posição dominante do entretenimento, o que não ocorria desde meados do século XIV.

Da mesma forma, outros autores vem sugerindo que práticas artísticas (sobretudo após a segunda metade do século XX) tem dedicado seus esforços a práticas que extrapolem a dimensão do que Schechner chamou de "representação da representação", problematizando a função de entretenimento atribuída às artes, a separação entre artista e espectador, ou ainda colocando em questão a fronteira que Schechner propôs entre transformação e transportação, arte e vida, dentre outras. Neste contexto, a arte da performance, tal como entendida na perspectiva estética, muito teria contribuído para abalar a visão de arte nas décadas de 1970 e 1980 (Andreas Huyssen, 1986 apud Féral, 2008: 199), não apenas emergindo enquanto uma nova modalidade artística (cujas práticas se apresentam diversas), mas atravessando diversas delas, a exemplo das artes plásticas, do teatro, da música, de formas também diversas. Neste sentido, sob certos aspectos ${ }^{10}$, os dos eixos a partir dos quais tem se pensado a arte hoje

\footnotetext{
${ }^{10}$ Digo sob certos aspectos porque em suas diferenças também repousam questões insolúveis, a exemplo da que o conceito de performance compartilha com o conceito de arte: se eles seriam ou não conceitos transculturais.
} 
não apenas poderiam ser conciliados analiticamente como se afetam mutuamente nas práticas culturais contemporâneas.

Autores que vem se propondo a refletir sobre performance ou sobre o teatro performativo ou pós dramático ${ }^{11}$ podem ser bastante elucidativos dos imbricamentos entre performance artística e ritual, que estamos nos propondo a tratar aqui. Cassiano Quilici (2015) se propõe a analisar experiências no teatro, performance e outras modalidades de arte que não tem voltado sua ênfase ao entretenimento, mas que tem buscado experiências de outra natureza, tendo como ponto de partida "o estranhamento com relação a um envolvimento automático com a existência". Para que estas experiências possam se desenvolver, nas palavras do autor:

é preciso desenvolver uma compreensão aguda do que está implicado na administração e ocupação crescente do próprio tempo dos indivíduos, das possibilidades de desconstrução de hábitos arraigados, da redescoberta da arte como uma espécie de trabalho singular, de cultivo de outras formas de vinculo social, e de expressão de possibilidades de transformação. (Quilici, 2015: 137).

A ideia da transformação poderia ser pensada como atrelada à noção de eficácia, entendendo esta última no sentido do sucesso obtido em processos de alteração do estado ou condição da pessoa num momento de transição ou de liminaridade. E é justamente partindo da noção de "experiência liminar" desenvolvida por Van Gennep, Turner e Schechner e fazendo referência a rituais tradicionais, que Quilici inicia sua análise do teatro e da performance, distinguindo-os das formas de grande "produção industrial do lazer". Propondo a característica de algo "extemporâneo" e marginal do teatro, se propõe a "enfatizar o sentido de afastamento das ocupações e dos hábitos da vida comum que a "liminaridade" evoca, abrindo espaço para outros modos do nosso "estar no mundo", que podem impulsionar a atividade artística" (Quilici, 2015: 136).

$\mathrm{Na}$ reflexão acerca da administração do "tempo livre" na sociedade contemporânea, Quilici aponta para a tendência ao impedimento de que se abram espaços vazios, momentos de suspensão onde possa emergir o que ele define como "inquietude de si”, interessante à investigação de uma certa ideia de arte, que a reconhece, penetra e transforma (Quilici 2015: 138). Retoma então os estudos de Michel Foucault, sobretudo "Hermenêutica do Sujeito" e a noção de "cuidado de si", entendida

${ }^{11}$ Teatro performativo foi o termo proposto por Josette Féral (2008) como alternativa ao termo proposto por Hans-Thies Lehmann (2007) para uma abordagem das transformações nas práticas teatrais influenciadas em grande medida por características da performance, descritas ao longo do texto. 
como "um conjunto de práticas e exercícios que configuravam modos de vida, ligadas a diferentes escolas filosóficas" da antiguidade greco-latina, configurando uma verdadeira “arte de viver" (Quilici, 2015: 138, 139).

As noções de "arte de viver" ou "arte da existência", como propõe Quilici (2015: 142), não se ajustam a categorias e divisões habituais, tais como teoria e prática, arte e vida, ética e estética, inovação e tradição, permitindo-nos questionar temas recorrentes na arte moderna e contemporânea. $\mathrm{O}$ primeiro deles diria respeito à abolir fronteiras entre arte e vida. A noção de "arte da existência", segundo o autor, "coloca a discussão da arte num patamar não só estético, mas ontológico: a arte torna-se uma forma de investigar a natureza do fazer e do agir humanos, de desvelar suas potencialidades mais altas” (Quilici, 2015: 142). Desta perspectiva, prossegue o autor, podemos melhor entender a proposição do performer e escultor Joseph Beuys, de que "cada homem é um artista". Tal concepção antropológica da arte não deve ser lida, porém, no sentido de um "vale tudo", mas apontaria para a arte "como parte do processo do homem realizar a sua própria humanidade" (Quilici, 2015: 142).

A noção de "arte da existência" apontaria para a arte enquanto "um modo de criar e cuidar das nossas formas de relação com o mundo e conosco mesmos" (Quilici, 2015: 143), para práticas de cuidado de si e produção de humanidade. E nesta direção poderia, tal como a noção de performance de Schechner, contemplar uma série de formas expressivas elaboradas por culturas diversas, situadas em diferentes tempos (como os exemplos evocados por Foucault) ou espaços (que na contemporaneidade habitam mundos e cosmologias diversas). Não por acaso, diversos artistas modernos e contemporâneos se interessaram em desenvolver trabalhos na relação com práticas que remontam a rituais de povos diversos, muitas vezes ligados a diferentes matrizes religiosas (do cristianismo, a religiões de matriz africana, budista,etc), mesmo que, conforme Quilili, influências como o Zen budismo (apenas para citar um exemplo) tenham sido assimiladas no meio artístico americano mais como um filosofia estética que como prática monástica (Quilici, 2015: 146).

As "atividades" de Allan Kaprow, pela relação de ruptura que evocam com relação aos cerimoniais cotidianos e na relação artista/público ${ }^{12}$, a prática performática

\footnotetext{
${ }^{12}$ Quilici assim descreve os exercícios de estranhamento do cotidiano propostos por Kaprow: "O modo de cumprimentar, de ceder a passagem para uma pessoa na porta, de sentir ou ouvir a própria respiração, as ações mais simples são rearranjadas em roteiros simples, que buscam trazer uma percepção estranhada do banal". (Quilici, 2015: 144). Viver, conforme propõe Quilici (2015: 145), se transformaria então numa experiência estética, mas esta não entendida como campo da produção humana, mas qualidade perceptiva.
} 
de Marina Abramovic que se aproxima de uma ideia de "ascese", assim como o trabalho de John Cage, que redefine a noção de música a partir dos ruídos cotidianos e da presença do silêncio (com influência do zen budismo), mas também práticas como as de Lygia Clark, Helio Oiticica (este sobretudo na relação com a expressividade das práticas sociais populares), dentre tantos outros, são alguns exemplos que, de diferentes formas contribuíram para uma redefinição da arte e do artista a partir de práticas perceptivas, existenciais e políticas. Noções como "acontecimento", assim como a de "artista propositor", mais do que criador, são algumas das noções que emergem destas práticas orientadas ao "aprofundamento da experiência perceptiva" (Quilici, 2015: 147).

A abordagem de Quilici nos possibilita observar os movimentos que (parte da) arte moderna e contemporânea tem feito de modo a desfazer as fronteiras que separam arte e vida, repensando definição e a função desta, que sob certos aspectos, dialogariam com a forma como podem ser concebidos não apenas os rituais, mas também outras formas expressivas relacionadas, por exemplo, aos grupos indígenas. Retomo aqui como pontos de conexão entre o fazer artístico e os rituais e outras formas expressivas a evocação da condição de estranhamento e liminaridade com relação à existência, a orientação para a transformação dos sujeitos (considerando que esta se opera de inúmeras formas), produzindo criativamente modos de relação com o mundo, com os outros e com a existência de modo menos automático e mais potente. Este fazer artístico independeria de um espaço específico para o jogo poético e da espetacularidade, inserindo a atividade artística na invisibilidade do cotidiano. Enquanto um dos meios de produzir a própria humanidade, esta abordagem da arte enquanto "arte da existência" se aproximaria de uma abordagem antropológica, que se propõe a refletir acerca das formas expressivas indígenas.

Para retornar à pintura corporal, acionada por Krenak na ação junto à Assembléia Constituinte, é com referência aos sentidos que ela apresenta nos contextos indígenas - enquanto uma arte da existência, voltada aos procedimentos constantes de produção de humanidade que proponho que seja abordada. No deslocamento da ação a um contexto público, político (em seu sentido estrito, governamental) a noção de transformação (do corpo e pessoa), eficácia e produção de humanidade seguem presentes, mas estas se dão de modo diverso, outras questões são postas em jogo e sobretudo, estas dizem respeito a outros sujeitos postos em relação e a dinâmicas diversas de marcam estas relações. A possibilidade de ação e eficácia das ações na 
esfera política (da Constituinte) não está desconectada porém, das possibilidades de ações e das relações cosmopolíticas indígenas, antes elas afetam-se mutuamente. Tanto a ação desenvolvida por Krenak está afetada por práticas indígenas como a eficácia visada na participação indígena na Assembléia Constituinte diz respeito à expectativa de reconhecimento e potencialização de seus modos específicos de existência.

Ainda com relação à ação de Krenak, considerando os deslocamentos que ela opera e seu possível imbricamento com relação à performance artística ${ }^{13}$, interessa destacar algumas características propostas por Féral entorno da performance ou do teatro performativo, vislumbrando possibilidades de aproximações. Dentre as características do teatro performativo destacadas por Féral (2008: 198) estão a transformação do ator em performer, implicando no engajamento do artista no sentido de um maior investimento de si mesmo; a descrição dos acontecimentos centrados na imagem e na ação em detrimento da representação e do texto; apelo a uma receptividade diversa do espectador. A ênfase na ação, no "fazer" (enfatizado por Schchner) enquanto ponto nevrálgico da performance cênica se conecta à noção de performatividade, cuja origem remonta às pesquisas lingüísticas de Austin e Searle, que enfatizavam os verbos performativos, que executam uma ação. Na performance, assim como no teatro performativo e outras modalidades de artes em que o "fazer" torna-se crucial para a existência da obra/evento, observa-se uma ênfase no processo, em detrimento do produto final, do objeto ou da representação. Este aspecto é associado por Féral enquanto amplificando o aspecto lúdico ${ }^{14}$ dos eventos e dos que participam dele (Féral, 2008: 203). Por não ser nem verdadeira nem falsa, a performance cênica, segundo Féral desconstrói códigos e opera por meio da ambigüidade das significações. Nas suas palavras:

a performance toma lugar no real e enfoca essa mesma realidade na qual se inscreve descontruindo-a, jogando com os códigos e as capacidades do espectador (...) Essa desconstrução passa por um jogo com os signos que se tornam instáveis, fluidos forçando o olhar do espectador a se adaptar incessantemente, a migrar de uma referência a outra, de um sistema de representação a outro, inscrevendo sempre a cena no lúdico e tentando por aí escapar da representação mimética . O performer instala a ambigüidade de significações, o deslocamento dos códigos, os deslizes de sentido (Féral, 2008: 203,204).

\footnotetext{
${ }^{13}$ Tal como sugere o curador de uma das exposições que ela possa ser lida.

${ }^{14}$ Quilici (2015) também chama a atenção para o aspecto lúdico de determinadas manifestações artísticas, "que carregam a potência do absurdo e do nonsense", desmanchando atitudes utilitárias e conversionais. Cita como exemplos tanto as "atividades" de Kaprow como as "máquinas inúteis" dadaístas. Nestes casos, o lúdico emerge enquanto estratégia crítica (Quilici, 2015: 145,146).
} 
Neste sentido, a ação de Krenak uma vez que parte do real ao mesmo tempo em que visa afetá-lo por meio de um fazer lúdico que desconstrói a realidade instaurada, desloca signos que se tornam fluidos, deslizantes, abertos a novos significados, encontra pontos em comum com a forma como Féral caracteriza o teatro performativo. $\mathrm{O}$ caráter lúdico da ação executada por Krenak também instensifica sua presença que implica também num maior engajamento dos presentes naquele acontecimento político e nos diversos contextos em que está sendo reativada. "A atenção do espectador se coloca na execução do gesto, na criação da forma, na dissolução dos signos e em sua reconstrução permanente. Uma estética da presença se instaura" (Féral, 2008: 209). A vividez e presença provocante do homem estão, para Hans-Thies Lehmann (2007: 225), em primeiro plano na performance artística e teatro performativo.

Com relação à inter-relação primordial no teatro performativo, que conecta performer, objetos e corpos e mais especificamente ao possível engajamento do espectador na ação, Féral aponta para a possibilidade de o espectador, apesar do recorrente convite ao engajamento, olhar para as ações sem engajar-se nela, de permanecer no exterior da ação sem ser absorvido por ela. Tal aspecto poderia ser um ponto importante de diferenciação entre a performance artística e os rituais realizados em contextos indígenas, por exemplo, em que neste último caso, o engajamento se apresenta enquanto condição de eficácia dos rituais e onde a noção de espectador não se faz presente. Dentre outras possíveis distinções entre as práticas rituais realizadas em sociedades tradicionais e aquelas desempenhadas nas performances artísticas ou no teatro performativo, Lehmann (2007: 230), sugere que no caso destes últimos o artista "não pode agir efetivamente como um xamã, portanto como um outsider socialmente reconhecido e admirado que transgride limites em favor dos outros". Na sociedade contemporânea, prossegue o autor, "cada artista realiza o ritual por sua própria conta" (Lehmann, 2007: 230).

Mesmo que uma abordagem acerca do ritual e da performance enquanto ferramentas teóricas possam apontar para pontos de contato entre rituais no campo ampliado do social e no campo restrito da arte, é preciso ter claro que as diferenças que estão em jogo não podem ser negligenciadas, sob pena de desconsiderar a que tais ações se propõe ou ainda mais, o que elas tem a dizer sobre o tempo, espaço e as relações onde estão inseridas. Também cabe apontar para os perigos de definições demasiado generalizantes dos rituais e performances artísticas, dada a grande diversidade em jogo 
em ambos os casos e a impossibilidade de esgotar o tema e comparações. Mesmo Lehmann, ao buscar caracterizar a arte da performance como orientada para a autotransformação do artista, isto é, propondo que as ações que realiza caracterizam-se por afetar o próprio corpo, tornando-se sujeito e objeto e não tanto preocupado com transformar o que se encontra fora dele, considera posteriormente que em casos como a performance ritual desenvolvida pelos acionistas de Viena, estes pretendiam também transformar o espectador através de suas ações.

A propósito da noção de transformação entorno da performance artística, Erika Fischer-Lichte (2008), tomando como caso de análise a performance "Lips of Thomas" $" 15$, de Marina Abramovic, ressalta, como o próprio título de seu livro indica, "o poder transformativo da performance”. Segundo a autora (2008: 12), na medida em que a artista desempenha ações efetivamente lesivas a seu corpo sem manifestar reações com relação a elas, ela desestabiliza tanto convenções da performance teatral quanto a capacidade de reação humana a determinadas situações. Com isso, também a audiência fica suspensa entre as normas e regras da arte e da vida cotidiana, entre imperativos éticos e estéticos, instaurando-se uma crise. O que os espectadores presenciam os afetam de modo imediato e físico. Conforme descrição da autora, a performance de Abramovic se encerra quando um dos espectadores retira a artista do curso das suas ações. Na situação criada, mais que interpretar ou buscar sentido às ações, o espectador é engajado numa experiência e envolve-se de tal maneira que torna-se ator, coresponsável pelos acontecimentos (2008: 13).

Para além da transformação em jogo com relação aos espectadores/atores, implicados nas ações enquanto co-responsáveis pelos acontecimentos em curso (a atividade destes, como a inatividade geram efeitos), a autora também ressalta possíveis relações entre as ações desempenhadas por Abramovic na performance em questão com práticas culturais (sobretudo rituais religiosos) ${ }^{16}$ que depositam na auto-flagelação uma promessa de transformação espiritual (2008: 14). Performances como esta acabam oscilando, conforme a autora, entre o ritual e o teatral ou espetacular. Na definição de Fischer-Lichte:

\footnotetext{
${ }^{15}$ Para uma descrição da performance ver Fischer-Lichte (2008).

${ }^{16}$ A autora menciona, por exemplo, que nos séculos XIII e XIV na Europa, procissões de flagelados eram realizadas conduzindo seus rituais publicamente em frente a grandes multidões (Fischer-Lichte, 2008: 13).
} 
It was ritualistic by the virtue of engendering a transformation of the performer and certain spectators but lacked the publicly recognized change in status or identity, as is often the case with rituals. It resembled a spectacle by virtue of eliciting awe and horror from the spectators, shocking and seducing them into becoming voyeurs (Fischer-Lichte, 2008: 15).

A implicação efetiva dos espectadores num drama que oscila entre o estético e o social ao ultrapassar a fronteira da representação via interferências efetivas no corpo da artista (que também oscila entre sujeito e objeto ${ }^{17}$ ) traz à arte da performance (e demais modalidades de arte por ela afetadas) a possibilidade de práticas que constantemente borram fronteiras por longo tempo sustentadas no campo da arte e da forma como esta é concebida com relação a outras esferas da vida, realinhando, através da proposição de eventos mais do que de obras de arte, a conexão entre sentir, pensar e agir (Fischer-Lichte, 2008: 18).

Retorno uma vez mais à ação de Krenak na Assembléia Constituinte e ao deslocamento destas imagens a exposições de arte, considerando parte das contribuições de Fischer-Lichte entorno da arte da performance. Esta última, como a ação política de Krenak, conjugam a um só tempo ações no campo do social/político/ético e da estética, visam transformações efetivas e ao mesmo tempo proporcionar uma experiência que afete o público envolvido de forma física, sensorial, emocional, a tal ponto que os convidem à ação. A conjunção do sentir, pensar e agir a que se refere Fischer-Lichte se conjugam na fala e gesto de Krenak.

Ao transformar o seu próprio corpo (em gesto que poderia ser aproximado ao do que fazem os artistas da performance) Krenak transforma o que era para ser um discurso político em um evento, onde os presentes na Assembléia Constituinte ficam suspensos entre a posição de "voyeur", engajando-se emocionalmente na ação, mas também são convocados, através da fala de Krenak, a agirem eticamente diante do evento em curso. A transformação de seu corpo e o estado de presença evocado, como já mencionado, dentre tantas leituras possíveis poderia ser evocativo de um momento de passagem e transformação do estatuto da pessoa (indígena) levando em conta sua posição na relação com o estado (de tutelado a sujeito de direito).

\footnotetext{
${ }^{17} \mathrm{O}$ que para Fischer-Lichte (2008: 17) constitui-se na redefinição de relações importantes às abordagens hermenêutica e semiótica da estética.
} 
Com relação à fala de Krenak, importante ressaltar que, assim como o gesto da pintura, esta também pode ser entendida como oscilando ou mesmo se constituindo em termos políticos e poéticos ao mesmo tempo. Tal como sugere Antonin Artaud (1993: 40) para uma proposta de teatro que leve em conta uma linguagem concreta ou "poesia no espaço", as palavras podem ser manipuladas enquanto objetos sólidos, com capacidade de abalar as coisas. Nas palavras do autor,

Fazer a metafísica da linguagem articulada é (...) devolver-lhe suas possibilidades de comoção física, é dividi-la e distribuí-la ativamente no espaço, é tomar as entonações de uma maneira concreta absoluta e devolver-lhes o poder que teriam de dilacerar e manifestar realmente alguma coisa (...) é enfim, considerar a linguagem sob a forma do Encantamento (Artaud, 1993: 40).

Muito poderia ser dito sobre a potência da fala e das palavras em relação a diversos grupos indígenas, palavras que são ditas, cantadas, que são imagens, poesias no espaço com capacidade de presentificar mundos. Entretanto, vou me deter ao caso em questão, enfatizando como a fala de Krenak intensificou sua própria materialidade ao ser enunciada junto ao gesto da pintura facial, pretendendo agir sobre os espectadores. Neste sentido, é interessante notar que a ideia de "encantamento" trazida por Arteaud também foi acionada por Alfred Gell (2005) para uma abordagem acerca da arte (ampliada a manifestações de outras sociedades) em artigo intitulado "A tecnologia do encantamento e o encantamento da tecnologia" e sob certos aspectos, os sentidos atribuídos por ambos os autores, se encontram.

A partir do exemplo das canoas das Ilhas Trobriand e suas proas esculpidas, Gell chama atenção para os atributos de agência e intencionalidade das obras de arte, que geram consequiências no âmbito das relações sociais. Segundo o autor, ao chegar em cada localidade, as canoas Trobriand geravam tal efeito de fascinação nos trobriandeses que os impelia a dar continuidade às relações de trocas e circulação de objetos que caracteriza o Kula, seu sistema cerimonial de trocas. Neste sentido, o autor argumenta que o poder dos objetos provem dos processos técnicos que eles personificam objetivamente, de modo que as perturbações causadas pelas proas são interpretadas como "evidências do poder mágico que emana da tábua" (Gell 2005: 45 e 47), das quais resultam sua razão social e eficácia. 
A fala e o gesto de Krenak também tem sua razão social e pretendem, através do fascínio gerado, da comoção física e emocional produzirem sua eficácia no âmbito das relações em questão. Krenak deixa claro nas suas palavras que as pessoas ali presentes são co-responsáveis pelo que está em jogo naquele tempo/espaço, referindo-se à ameaça de restrição dos direitos indígenas na redação/homologação da Constituição Federal de modo mais restrito, mas também à responsabilidade do Estado pela violência histórica sofrida pelos povos indígenas no Brasil. Uma ação que evoca o sentir, pensar a agir (como sugeriu Fischer-Lichte, 2008) de quem está presente na Assembléia. Mesmo que a ação dos presentes não possa se efetivar no exato instante de sua fala, ele ressalta a responsabilidade de quem está presente, cuja possibilidade de atuação está no horizonte dos acontecimentos em jogo naquele momento. As consequiências desejadas no âmbito das relações sociais, conforme propôs Gell (2005), assim a transformação dos espectadores em atores, conforme sinalizou Fischer-Lichte ao tratar das performances artísticas, se fazem presentes na ação de Krenak no contexto da Assembleia Constituinte.

Ao serem deslocadas para espaços de exposição de arte, contudo, as imagens da ação de Krenak possibilitam a outro público sentir e pensar diante do acontecimento que pode ser revivido, atualizado. Mesmo deslocada de seu contexto original, a ação não deixa de agir no mundo e sobre as pessoas que com ela estabelecem relação. Gera efeitos nos espectadores, assim como tem integrado um movimento potencialmente transformador no campo das artes num momento em que a (parte da) arte contemporânea reivindica para si reaproximações com o político, com questões urgentes em nosso tempo e com o interesse de uma revisão (ainda tímida) da história colonialista que desconsidera as práticas expressivas, o pensamento e os modos de existência dos povos indígenas na história do Brasil, posicionando-se diante das forças políticas dominantes e atuantes no Estado que tem desconsiderado os direitos indígenas garantidos pela Constituição de 1988.

Entretanto, se a possibilidade de ação dos espectadores estava clara na execução da performance na Assembléia Constituinte, fica em aberto no âmbito da reprodução das imagens da ação em exposições de arte contemporânea de que forma o espectador pode engajar-se a ponto de tornar-se ator e co-responsável pelo que está em jogo. Uma questão que pode apontar tanto para os limites desta reprodução em relação à ação original quanto, pela atualidade das questões levantadas por Krenak e potência de 
sua fala e gesto, impulsionar possibilidades de ação em aberto, que precisam ser ativadas no contexto atual.

\section{Outras palavras, pensamentos e ações}

Em fala durante a programação das "Conversas para adiar o fim do mundo", "Poéticas e resistências indígenas", realizada em 15 de novembro de 2016 como parte da intervenção de Bené Fonteles na 32 $2^{\mathrm{a}}$ Bienal de São Paulo, Ailton Krenak destaca em sua fala a importância de juntar pensamento e ação e a urgência por ações que levem em conta o que Davi Kopenawa naquela ocasião chamou de "ética da terra planeta". Gostaria, pois, de trazer alguns aspectos apontados por Ailton Krenak diante da circulação das imagens de sua ação na Assembléia Constituinte em contextos de exposições de arte e de sua contribuição em processos de curadoria de exposições de arte e festivais de cinema indígena.

Nos últimos anos Ailton Krenak esteve à frente da organização de pelo menos dois eventos importantes voltados especificamente à produção de arte e cinema indígena: a exposição "Mira! Artes visuais contemporâneas dos povos indígenas" e a “Aldeia SP: Bienal de cinema indígena". Além disso, contribuiu para os "Dias de Estudo" da 32a Bienal de São Paulo (dentre outras atividades desta mostra) e participou de exposições com obras de pintura, além das imagens da ação de que estamos tratando ao longo das últimas páginas e de livros que tem publicado. Krenak ressalta a importância de que os povos indígenas possam estar presentes e atuantes em diversos contextos, dentre os quais o da própria arte, sem deixar de chamar atenção, porém, às especificidades de suas produções (de pensamento, de modos de relação) e às contradições e perigos destes processos.

Com relação ao modo como os indígenas vem se relacionando com o que é contemporâneo e se fazendo presente em produções artísticas, cinematográficas, literárias, Krenak, a partir de diálogo com Davi Kopenawa ${ }^{18}$, declara:

\footnotetext{
18 Durante a mesa "Resistências e poéticas indígenas" na $32^{\mathrm{a}}$ Bienal de São Paulo, Davi Kopenawa, comentando sobre o livro que é co-autor "A queda do céu", declara que ele não escreveria um segundo livro. Já o escreveu e não escreverá mais, pois difundir seu pensamento que pretende sensibilizar os nãoindígenas também implica, de alguma maneira na inserção do mundo da mercadoria que ele critica: na produção de uma mercadoria de papel que implica na destruição de árvores, seres vivos que integram o mundo animado ao qual ele propõe que cuidemos
} 
Nós estamos sendo empurrados para novas percepções e maneiras de interagir no mundo e com diferentes culturas. E vamos aprendendo com dificuldade, pagando um preço muito alto, assistindo as árvores que são pessoas, irmãs, sendo erradicadas assim como as pessoas também. (Ailton Krenak) ${ }^{19}$

Por outro lado, através das novas plataformas de produção e circulação do pensamento indígena, Krenak vê também a possibilidade de transfigurar os conhecimentos indígenas de modo que possam ser acessados por um maior número de pessoas e que a partir disso possam contribuir para a luta e resistência indígena e emergência de outros paradigmas de produção de pensamento, das artes mas também de humanidade e mundo. Nas palavras de Krenak: "Para mim, tocar nesta questão do paradigma do pensamento é a função seja do audiovisual, seja de outros objetos que podem ser apreciados como arte e é o trabalho que a gente faz e que tem que fazer" ${ }^{20}$. A transfiguração, como chamou Krenak, das cosmovisões indígenas a diferentes plataformas e sua circulação em diversos contextos podem atribuir a elas outras e novas dimensões e funções, que podem ser interessantes desde que sirvam a seu fortalecimento e dos modos de vida que lhe são inerentes.

Ao perguntar a Krenak em que medida interessaria a circulação destas produções em contextos artísticos, ele ressalta que é sobretudo nestes espaços que as pessoas param para olhar, refletir.: "no movimento do cotidiano, na rotina, a maioria de nós está ocupada com a subsistência, com a sobrevivência, ocupada em dar resposta para as coisas práticas. Tem dificuldade de integrar no seu cotidiano, na sua vida o sentido de beleza, de subjetividade, de transcendência que é atribuído ao fazer um balaio, uma rede, um pote, uma casa ${ }^{21}$,, diz Krenak. Levar em conta as possibilidades da arte e a importância da presença de produções indígenas nestes contextos não implica, porém que eles se identifiquem enquanto "artistas", pelo menos no sentido estrito do termo, assim como requer que estejam atentos aos perigos que os deslocamentos e circulação de pessoas e objetos em contextos de arte podem trazer. Krenak aponta as limitações das definições de arte e artista quando estes passam a estar atrelados unicamente à produção de mercadorias, reivindicando um outro lugar para os produtores e a produção indígena. Tratando de seu lugar enquanto "não-artista" e das exposições e mostras que esteve presente enquanto organizador, declara que:

\footnotetext{
19 Fala durante a mesa "Resistências e poéticas indígenas" na $32^{\mathrm{a}}$ Bienal de São Paulo, em 15 de novembro de 2016.

${ }^{20}$ Entrevista concedida a autora em 8 outubro de 2016.

${ }^{21}$ Entrevista concedida a autora em 8 outubro de 2016.
} 
A natureza da arte é ser transformadora. O que eu vejo é a limitação da ideia de arte que o ocidente consagrou. Na cosmovisão indígena não existe uma separação entre viver e fazer qualquer outra coisa. Não tem artista. O que me preocupa é uma tendência crescente de aproximação dessa criação chamada "arte indígena", chegar ao ponto de perder a identidade e começar a ter artista. Eu não sou um artista. E eu não faria uma lista de pessoas que seriam artistas. Quando a gente fez a "Mira!" a gente reuniu obras de diferentes pessoas, diferentes culturas, mas a gente não chamou ninguém de "os artistas". Assim como agora na Bienal de cinema a gente evitou chamar o pessoal de cineastas. O catálogo chama eles de realizadores. Eles são realizadores. Fizeram isso. Não tem ninguém afirmando que eles vão ter uma carreira profissional fazendo filmes. Essas pessoas caçam, pescam, fazem roça, casa e eventualmente um ou outro fizeram filmes. (Ailton Krenak, outubro de 2016) ${ }^{22}$.

Fazer-se presente nestes espaços que ampliam as possibilidades de visibilidade ao pensamento indígena, de relação e abertura a outras formas de se pensar/fazer arte e cinema buscando uma "revolta do olhar", ${ }^{2}$, fazendo frente e não sucumbindo às linguagens subalternas da grande mídia ou mesmo do mercado da arte, orientadas por interesses que reproduzem lógicas colonizadoras dos corpos, do pensamento, da diferença, conferem à presença indígena nestes espaços, suas produções e ações o caráter de opacidade proposto por Édouard Glissant (2011). Ao tratar da relação entre transparência e opacidade, refletindo acerca da relação entre o modelo de conhecimento ocidental que serviu à conquista e descoberta e a modelos de conhecimento de outros povos, Glissant descreve:

Há ainda centros de dominação, mas concorda-se que já não existem lugares superiores dotados da exclusividade do saber, metrópoles de conhecimento. À generalidade abstrata desse conhecimento, que foi ligado ao espírito de conquista e de descoberta, sobrepõe-se agora uma materialidade densa da presença dos povos. $\mathrm{O}$ seu conhecimento mudou, ou pelo menos a epistemologia que dele fazemos. A sua transparência, ou seja, no fundo a sua legitimidade, já não assenta num Direito. A transparência já não surge como fundo do espelho onde a humanidade ocidental refletia o mundo à sua imagem; no fundo do espelho há agora opacidade, todo um sedimento depositado por povos, sedimento fértil, mas afinal incerto, inexplorado, ainda hoje e quase sempre negado ou ofuscado, cuja presença insistente não podemos deixar de viver" (Glissant, 2011: 107).

\footnotetext{
${ }^{22}$ Entrevista concedida a autora em 8 outubro de 2016.

${ }^{23}$ Noção proposta por Krenak ao longo da realização da Aldeia SP: Bienal de cinema indígena.
} 
Ainda mais que insistir na presença e no direito à diferença, Glissant reivindica o direito à opacidade, de modo que a diferença não seja reduzida, para fins comparativos, no interior das matrizes do pensamento ocidental. Enquanto singularidades não redutíveis, "as opacidades podem coexistir, confluir, tecendo tramas cuja verdadeira compreensão incidiria na textura dessa teia e não na natureza dos componentes", declara Glissant (2011: 180). O referente se tornaria então, ao invés da Humanidade, "a divergência exultante das humanidades", fundante da Relação. Neste sentido, a reivindicação de Krenak acerca da não redução do pensamento indígena e suas produções a determinados parâmetros da arte e do pensamento ocidental e ao mesmo tempo o interesse da presença indígena na contemporaneidade e da enunciação de seu pensamento por meio de plataformas diversas, em espaços onde o diálogo possa ocorrer possibilitando participação, diálogo, abertura, vai ao encontro do que Glissant chama de direito à opacidade e de uma poética da Relação. Quando Krenak diz que ele não é artista, ele resiste à redução a um modelo determinado de artista que a meu ver, nós também precisamos reivindicar que se abra, seja mais plural, lugar onde possa viver a opacidade e multiplicidade.

Tanto a mostra Mira! quanto as bienais de cinema indígena tem revelado o interesse e empenho de realizadores indígenas de configurar relações paritárias em termos de reflexões e produção de pensamento, que possam gerar trocas enriquecedoras. Da mesma forma, curadores e historiadores de arte vêm se interessando em ampliar o debate acerca do lugar da arte diante de grandes questões e muitas incertezas que rondam a situação política, econômica, social, ambiental atual. A 32a Bienal de São Paulo se propôs a problematizar a incerteza, entendendo-a como condição de nossos tempos, a exaustão de determinados modelos ocidentais de produção de pensamento e relação no mundo. O interesse em vislumbrar novas possibilidades de fazer arte e desta apontar para novas possibilidades de pensamento, produção e relação e de incentivar processos de experimentação que os distinguiam de obras e processos atrelados ao mercado de arte (feiras, galerias), possibilitou aproximações com o pensamento indígena. Para Ailton Krenak, a proposta da $32^{\mathrm{a}}$ Bienal "abriu frestas para outros paradigmas, como por exemplo, para o pensamento mágico, pensamento indígena, do xamã, que dialoga em outros termos"24. O que não significa, segundo ele, que os indígenas conquistaram algum espaço no mundo da arte. Só saberemos com o tempo se

\footnotetext{
${ }^{24}$ Entrevista concedida a autora em 8 outubro de 2016.
} 
artistas indígenas, tais como os apresentados na Mira! ou na Aldeia SP, estarão presentes em maior número em mostras como a Bienal de São Paulo ${ }^{25}$.

Se, tal como propôs Krenak, tocar na questão dos paradigmas do pensamento seria a principal função das ações e produções indígenas que estariam sendo apreciadas como arte no contexto atual, gostaria de finalizar este texto com outra fala sua, realizada durante a $32^{a}$ Bienal de São Paulo, onde estes paradigmas são enunciados. Esta fala, assim como aquela que realizou na Assembléia Constituinte, chama a atenção para o gesto/ação performática de corpos que, resilientes e resistentes, insistem em viver.

Ailton Krenak descreve como dramática a situação que não apenas os povos indígenas, mas todos estamos vivendo. No contexto político atual, tanto os direitos indígenas quanto os direitos ambientais conquistados nas décadas de 1970/1980 se encontram em grande medida ameaçados por agressões movidas "pelo poder econômico, pela ganância, pela ignorância do que significa ser um povo indígena"26.

Em novembro de 2015, o rompimento da barragem de rejeitos de Bento Rodrigues, dentre incontáveis danos, deixou em coma o Rio Doce, ao qual os Krenak referem como Watu, o avô. Fazendo mais uma vez de sua fala um ato poético e político, fazendo emergir nas frestas um pensamento que faça frente à lógica da mercadoria, que objetifica a terra e os seres que nela habitam, Krenak evoca o gesto performático de Watu $^{27}$. Na sabedoria do rio, entidade vivente, que diante de tamanhas agressões insiste no movimento para não morrer, outra ética e arte da existência são evocadas. Nas palavras de Krenak:

\footnotetext{
${ }^{25}$ Embora comparativamente, a $32^{\mathrm{a}}$ Bienal tenha tido maior expressividade de obras que trabalharam com temas que tocam em questões indígenas e que estes tenham colaborado em trabalhos de artistas, participado de eventos que antecederam e seguiram ocorrendo ao longo da mostra e que produções indígenas tenham sido mostradas pelo Coletivo Vídeo nas Aldeias (o que já é bastante interessante e importante), realizadores indígenas que estão reivindicando sua presença no campo da arte contemporânea ainda não tem espaço expressivo nestas e outras mostras que tem buscado aproximar as artes indígenas e contemporânea.

${ }^{26}$ Trecho da fala de Krenak na Assembleia Constituinte, 1987.

27 Ao contrário da epistemologia da modernidade ocidental em que conhecer é objetivar, o pensamento xamânico evocado por Krenak, "é um modo de agir que implica um modo de conhecer, ou antes, um ideal de conhecimento (...) em que conhecer é personificar", visa um "algo" que é "alguém", sujeito, agente, pessoa (Viveiros de Castro, 2002: 358).
} 
Vamos pensar nessa mágica de um rio que mergulha quando o que oferecem pra ele não é o lugar próprio para um rio. Eu acho que aquele rio [Watu - Rio Doce] também juntou ação com o instante que estamos vivendo. O nosso rio é subterrâneo hoje e nós vemos correr uma lama. (...) Nós estamos vendo e agindo diante de uma situação que é mesmo escandalosa. Nós já chegamos ao ponto não só de ameaçar, mas fazer fugir de nossas paisagens até mesmo um rio. Então, que essa incerteza que estamos experimentando possa mover a nossa vontade por ação. Não uma ação pontual, sobre uma ou outra coisa. Mas pensar essa terra-planeta como um organismo vivo que exige de nós, seus filhotes, que a gente tenha isso que o nosso pajé falou, ética da terra-planeta. (Ailton Krenak, 15 de novembro de 2016).

\section{Referências}

ADORNOS do Brasil Indígena: Resistências contemporâneas. São Paulo: SESC, USP (corealização), 2016. Catálogo da Exposição realizada no SESC Pinheiros, em São Paulo, de 7 de setembro de 2016 a 8 de janeiro de 2017.

ARTAUD, Antonin. A encenação e a metafísica. In: O Teatro e seu duplo. Martins Fontes, São Paulo, 1993.

CAIXETA, Ruben. Entrevista com Vincent Carelli. In: Catálogo do Forumdoc. BH 2009. 13 Festival do Filme Documentário e Etnográfico. Fórum de Antropologia, Cinema e Vídeo. Belo Horizonte, 2009, p.149-160.

CATÁLOGO DA 29ª BIENAL DE SÃO PAULO: Há sempre um copo de mar para um homem navegar/ Curadores Agnaldo Farias, Moacir dos Anjos - São Paulo: Fundação Bienal de São Paulo, 2010.

CATÁlogo DA EXPOSIÇÃO A QUEDA DO CÉU. Curador Moacir dos Anjos, 2015. Catálogo da Exposição realizada no Paço das Artes, em São Paulo de 10 de abril a 05 de junho de 2015 e no SESC Rio Preto, em São José do Rio Preto de 18 de maio a 28 de agosto de 2016. CEDI - Centro Ecumênico de Documentação e Informação, São Paulo. Povos Indígenas no Brasil 1987/88/89/90. (Série Aconteceu Especial, 18). São Paulo, CEDI, 1991.

DOS ANJOS, Moacir. Adorno e Luta. In: Adornos do Brasil Indígena: Resistências contemporâneas. São Paulo: SESC, USP (co-realização), 2016. Catálogo da Exposição realizada no SESC Pinheiros, em São Paulo, de 7 de setembro de 2016 a 8 de janeiro de 2017.

FÉRAL, Josette. Por uma poética da performatividade: o teatro performativo. In: Sala Preta \#8, São Paulo: Revista do PPG em Artes Cênicas, 2008.p.197-210.

FERRAZ, Marcos G. O adorno como arma da resistência indígena. In: Arte!Brasileiros. 3 de outubro de 2016. Disponível em: http://brasileiros.com.br

FISCHER-LICHTE, Erika. The transformative power of performance. In: The transformative power of performance. London and New York: Routledge, 2008. p.11-23.

GLISSANT, Édouard. Poética da Relação. Sextante Editora. Porto, 2011.

GELL, Alfred. A tecnologia do encanto e o encanto da tecnologia. In: Concinnitas, ano 6, volume 1, número 8, 2005.

ÍNDIO CIDADÃO? Direção: Rodrigo Siqueira. Brasília: 7G Documenta/Machado Filmes, 2014. Documentário, 52 min.

LEHMANN, Hans-Thies. Teatro e Performance. In: Teatro Pós-dramático. São Paulo, Cosac Naify, 2007. p. 223-233.

MÜLLER, Regina Polo. Ritual, Schechner e performance. In: Horizontes Antropológicos ano 11, n.4, 2005. p. 67-86.

O BRASIL DOS ÍNDIOS: UM ARQUIVO ABERTO. Publicação comissionada pela Fundação Bienal de São Paulo em ocasião da $32^{\text {a }}$ Bienal de São Paulo - Incerteza Viva. Vídeo nas Aldeias, 2016.

QUILICI. Cassiano Sydow. Teatro, performance e "inquietude de si". In: O ator-performer e as poéticas da transformação de si. São Paulo: Annablume, 2015. p. 135-150. 
RADIO YANDÊ. Documentário mostra luta pela conquista da cidadania e trajetória do movimento indígena. Entrevista com Rodrigo Siqueira, 9 de março de 2015. Disponível em: http://radioyande.com/

SCHECHNER, Richard. Ritual and performance. In: Ingold, T. (Ed). Anthropology (encyclopedia). London, Routledge, 1994.

SCHECHNER, Richard. "Pontos de contato" revisitados. In: Antropologia e performance: Ensaios Napedra. DAWSEY, John et al.(Org.). São Paulo: Terceiro nome, 2013. p.37-65

TURNER, Victor. O Processo Ritual Estrutura e Anti Estrutura. São Paulo: Vozes, 1974.

VIVEIROS DE CASTRO, Eduardo. "Perspectivismo e multinaturalismo na América indígena". In: A inconstância da alma selvagem e outros ensaios de antropologia. São Paulo, Cosac \& Naify, 2002.

Recebido em: 31/01/2017.

Aprovado em: 30/03/2017. 